\title{
The Impact of Brand Familiarity on Online and Offline Media Synergy
}

\begin{abstract}
Rooted in the Integrated Marketing Communication framework, this paper conceptualizes how brand familiarity affects online and cross-channel synergies. The empirical analysis uses Bayesian Vector Autoregressive models to estimate long-term elasticities for four brands. The authors distinguish customer-initiated communication (typically online) from firm-initiated communication (typically offline). Their results indicate that within-online synergy is higher than online-offline synergy for both familiar brands but not for both unfamiliar brands. Managers of unfamiliar brands may obtain substantial synergy from offline marketing spending, even though its direct elasticity pales in comparison with that of online media while managers of familiar brands can generate more synergy by investing in different online media.
\end{abstract}

Keywords: marketing effectiveness, online paid, owned and earned media, synergy, integrated marketing communications, brand familiarity, Bayesian Vector Autoregression. 
"Getting paid, owned and earned media to work in tandem, enhancing the effect of each is the ultimate goal," Alistair Green, head of strategy, Mindshare (2012).

"You cannot build a brand simply on the Internet. You have to go offline," J.G. Sandom Chairman and CEO at Mnemania (Pfeiffer and Zinnbauer 2010).

Since the introduction of the first banner ad in 1994, online advertising has redefined the global advertising landscape. Spending in the sector has continued to grow, reaching $\$ 117.60$ billion globally in 2013 with expectations for this to reach $\$ 132.62$ billion in 2014 and $\$ 173.12$ billion by 2017 (EMarketer 2013). A key reason for this popularity is that companies typically only pay for online media when prospective customers take action, for example, by clicking on the ad or visiting the site (Bowman and Narayandas 2001). In contrast to offline advertising spending, the long-term effectiveness of online media is not well understood (Hanssens 2009). While Li and Kannan (2014) found a low value of paid search response for a well-known hospitality brand, they acknowledge that this result may be driven by the strength of the one brand under study and call for future research. Insights on online media effectiveness are important to Chief Marketing Officers, who are keenly interested in its return on investment (CMO Survey 2013). Beyond the individual effectiveness of online media, their synergy within-online and with offline media has only recently started to attract academic scrutiny (Dinner, van Heerde and Neslin 2014; Naik and Peters 2009). Which media types are most complementary with each other and thus produce synergy ${ }^{1}$ for different brands?

We address this research question by assessing whether and how within-online synergy and cross-channel synergy vary across brands. Building on research regarding

\footnotetext{
${ }^{1}$ Throughout the paper, 'synergy' is bidirectional, as it arises when the combined effect or impact of a number of media activities is greater than the sum of their individual effects on sales (Schultz, Block and Raman 2012).
} 
the effectiveness of banner ads (e.g., Manchanda, Dube, Goh and Chintagunta 2006), paid search (e.g., Wiesel, Pauwels and Arts 2011; Dinner, van Heerde and Neslin 2014), and social media conversations (e.g., Godes and Mayzlin 2004; Moe and Trusov 2011; Sonnier, McAlister and Rutz 2011). We offer three contributions.

First, we provide a conceptual framework and an empirical analysis of how brand familiarity influences online and cross-channel media synergy. Second, we analyze longterm online media elasticities and synergies and provide empirical insights into the interplay between online and offline media in driving synergy. As hypothesized, for relatively unknown brands, the synergy of online media with offline media (crosschannel synergy) is higher than within-online synergy. Finally, we illustrate the managerial implications by comparing optimal budget allocations in the presence and absence of such synergy. For the unfamiliar search brand analyzed in a previously published paper (Wiesel et al. 2011), we show a dramatic change in the optimal budget allocation, with the recommended online/offline allocation moving from $91 \%$ / $9 \%$ to $45 \%$ / $55 \%$ after incorporating synergy.

The rest of the article is organized as follows. After a description of related work, we develop a conceptual framework based on which we offer hypotheses on online media synergy with each other and with offline media. In the research methodology section, we propose our Bayesian VAR econometric approach. We then describe the data set and present our key findings on synergy as well as sales effectiveness of online and offline media, and offer managerial implications for marketing budget allocation optimization. We conclude the paper with a summary and a discussion of implications for practitioners and academics. 


\section{RESEARCH CONTEXT AND CONCEPTUAL FRAMEWORK}

This section provides an overview of the extant research on online versus offline media and the role of synergy within and among these media. Building on this, we propose a conceptual framework that characterizes conditions under which offline and online media should be most complementary with each other and thus produce synergy.

\section{Customer-Initiated (Online) Media versus Firm-Initiated (Offline) Media}

Recent marketing literature distinguishes between customer-initiated (often online) and firm-initiated (often offline) media. Customer-initiated media (hereafter 'online media' for ease of exposition) charge companies only when (potential) customers actively click on, search for and/or engage in online conversations about the company's offerings (Bowman and Narayandas 2001; Gartner 2008; Hoffman and Fodor 2010; Wiesel et al. 2011). ${ }^{2}$ In contrast, firm-initiated media (hereafter 'offline media' for ease of exposition) can be increased by companies without specific customer action, e.g., by doubling the TV broadcasting time. Online media spending has surpassed offline radio and magazine spending (Danaher and Dagger 2013), widening the call for research on its effectiveness from both marketing academics and practitioners.

While online media used to be classified as paid, owned and earned online media (Corcoran 2009), these distinctions are increasingly blurry. Still, the classification offers a useful starting point for describing different types of online media.

\footnotetext{
${ }^{2}$ Data on the fixed costs of setting up and running a website and hiring online media experts (online media) or developing traditional marketing messages are not generally available. We indirectly capture such efforts reflected in the higher effectiveness of weekly spending on online media as is typical in previous work (Wiesel et al. 2011).
} 
Paid online media include online banner ads, affiliate marketing and paid search. Affiliate marketing (Gallaugher, Auger and Barnir 2001) involves paying affiliates (e.g., Amazon) a percentage of the sales revenue generated when a customer is redirected from the website of the affiliate to that of the company (e.g., Sony). Hoffman and Novak (2000) find a low effectiveness of online banner ads, and propose affiliate marketing as a more efficient way of customer acquisition. More recently, paid search has gained popularity with US companies spending more than $40 \%$ of the total online advertising dollars for paid search (Animesh, Ramachandran, and Viswanathan 2010). In paid search (e.g., Google's AdWords), advertisers bid for a position close to the top in the listing of the paid search results which are displayed prominently on the top or side of organic search results. Two recent studies find little, if any, incremental sales impact from paid search for the studied brand, as verified in a field experiment of shutting off paid search (Blake et al. 2015; Li and Kannan 2014).

Owned media includes the online media assets owned by a company, such as its websites and their search engine optimization qualities, as reflected in organic search results. Prospective customers visit a brand's website to obtain more information regarding the attractiveness of the product or service vis-à-vis competing offers ( $\mathrm{Li}$ and Kannan 2014). The strength of owned media is reflected in the company's ranking in organic search (Yang and Ghose 2010) and in the amount of 'direct visits', i.e. visitors that type the company's name directly into the URL (Li and Kannan 2014). Such 'typein' traffic may include loyal, repeat customers, and late-stage buyers who may have already visited the site but needed time to make the purchase decision (Bustos 2008). 
Earned media arises organically from consumers (Lieb and Owyang 2012). This includes social media about the brand which includes blogging, microblogging (e.g. Twitter), co-creation, social bookmarking, forums and discussion boards, product reviews, social networks (e.g. Facebook) and video- and photo-sharing (Hoffman and Fodor 2010). Consumers participate in these activities due to their desire to connect, create, control and consume content (ibid). However, earned media are increasingly 'fertilized' by company employees (Trusov et al. 2009), with the blurred lines of, for example, sharing sponsored content and native advertising (Wegert 2015). Foresee Results (2011) reports high purchase conversion rates for visitors generated by social media. However, social media has drawn criticism given the lack of consistent evidence on sales results. For example, both Burger King and Pepsi reported poor sales performance from their social media campaigns despite scoring well in terms of traffic and customer engagement (Baskin 2011).

While the effectiveness of these separate online marketing actions has seen much recent research attention, their synergy with each other, i.e. within-online synergy and with offline media, i.e. cross-channel synergy, remains an important unresolved puzzle.

\section{Synergy in Online Media and Offline Media}

Synergy in media arises when the combined effect or impact of a number of media activities is greater than the sum of their individual effects on sales (Schultz, Block and Raman 2012). Social psychologists propose that the greater the number of sources perceived to advocate a position, the higher is the perceived credibility (Cacioppo and Petty 1979) and hence purchase intention (MacInnis and Jaworski 1989). Synergy has been demonstrated within offline media (e.g. Edell and Keller 1989; Raman and Naik 
2004), across offline and online media (e.g. Chang and Thorson 2004; Naik and Peters 2009; Reimer, Rutz and Pauwels 2014) and within online media (e.g. Schultz, Block and Raman 2012; Kireyev, Gupta and Pauwels 2013; Li and Kannan 2014). However, virtually all these studies analyze a single company, and do not examine to what extent synergies differ for familiar versus unfamiliar brands. The presence of within-online synergy implies a stronger allocation towards online media actions, while cross-channel synergy implies a stronger role for offline marketing communication, which typically has lower sales elasticity by itself (Wiesel et al. 2011). Our key thesis is that synergy should differ for brands with high versus low familiarity among prospective customers, as summarized in table 1. Brand familiarity captures consumers' brand knowledge and brand associations that exist within a consumer's memory, representing one of the components of customer-level brand equity (Keller and Lehmann 2006). ${ }^{3}$

---- Insert Table 1 around here ----

Selective attention theory (Kahneman 1973) implies that the use of multiple media with repetition of ads lead to increased attention and elaboration. Attention is highest for stimuli that are either both complex and familiar or are both simple and novel, as compared to other combinations. Thus, if the stimulus is complex, the message needs to be repeated in more media to increase familiarity. For less familiar brands, selective attention theory implies managers should use multiple tools and invest in integrated marketing communications (Stammerjohan et al. 2005). Unfamiliar brands still have to build brand equity; they do not have the luxury to simply leverage existing brand equity

\footnotetext{
${ }^{3}$ Brand equity also has other components (Keller 1993) but distinguishing these components is beyond the scope of this paper.
} 
online (Pfeiffer and Zinnbauer 2010). Indeed, Ilfeld and Winer (2002) suggest that offline firm-initiated communication will drive website traffic by increasing consumer awareness. Additionally, high spending on both online and offline media may signal a brand's quality and create credibility. Other studies on unfamiliar brands showed that the combination of offline and online advertising is more effective than repeated exposures in either medium (Chang and Thorson 2004; Dijkstra, Buijtels and Van Raaij 2005). Therefore, we propose that:

H1: For unfamiliar brands, cross-channel synergy is higher than within-online synergy.

In contrast, familiar brands run the risk of boring consumers (Anand and Sternthal 1990; Campbell and Keller 2003) and obtain little synergy among offline media actions (Stammerjohan et al. 2005). Instead, familiar brands achieve higher click-through on their online paid ads and more organic visits to their website (e.g. Yang and Ghose 2010; Ilfeld and Winer 2002), thanks to their salient, rich and positive associations in consumers' minds (Keller 1993). For instance, Vanguard was surprised to learn that most clicks on its banner ads came from existing customers (McGovern and Quelch 2007). Such paid exposure makes the existing link with the familiar brand more salient, and drives consumers to the brand's owned media. Therefore, we propose that:

H2: For familiar brands, within-online synergy is higher than cross-channel synergy.

We investigate these hypotheses for unfamiliar and familiar brands for brands in four different categories, to help understand the generalizability of the recent findings in the literature. 


\section{RESEARCH METHODOLOGY}

\section{Bayesian Vector Autoregressive Models}

Our objectives and conceptual framework impose specific modeling requirements that we outline here. First, we require a model that simultaneously incorporates several online and offline marketing variables in addition to brand performance. Second, we need to link the marketing variables to brand performance both directly and indirectly through each other. In addition, the model needs to control for the effects of other marketing actions such as feature and display as well as seasonality to avoid omitted variable bias. Third, as the online and offline actions can influence each other over time, we need a model that will accommodate these dynamic dependencies. Fourth, we need to obtain immediate and cumulative effects of marketing variables on brand performance. Such requirements have led many previous researchers to specify a Vector Autoregression (VAR) model (e.g. Trusov et al. 2009, Wiesel et al. 2011). These models explicitly deal with likely endogeneity (e.g., TV campaigns increase website visits, which increase sales) by modeling each variable endogenously, i.e. explained by the dynamic system.

Unrestricted estimation of VAR models risks over-parametrization because the parameter space proliferates with the number of endogenous variables, which include in our case brand performance and several forms of online media and offline marketing. ${ }^{4}$ In a standard VAR model, a large number of parameters may produce a good model fit, but still result in multicollinearity and loss of degrees of freedom, which in turn may lead to

\footnotetext{
${ }^{4}$ In our empirical application, the total number of parameters estimated for brand A, B, C and D is 198, 280, 280, and 264 respectively. Since this is infeasible with standard VAR approach, we use Bayesian VAR modeling, which imposes stochastic constraints on the parameters of the VAR model.
} 
inefficient estimates and poor performance in the impulse-response functions. Bayesian models alleviate such issues thanks to shrinkage, which imposes restrictions on the parameters of the VAR model. We therefore outline a Bayesian VAR model (Sims and Zha 1998; Horvath and Fok 2013) specification that meets our requirements.

Bayesian Vector Autoregressive (BVAR) models are formulated in Litterman (1986) and Doan, Litterman and Sims (1984), but have seen little application in marketing (for an exception see Horvarth and Fok 2013). Several priors have been used in the econometrics literature to estimate the Bayesian VAR models, including Minnesota prior and NormalWishart prior (e.g., Banbura, Giannone and Reichlin 2010; Ciccarelli and Rebucci 2003; Kadiyala and Karlsson 1997; Sims and Zha 1998). Recently, Banbura, Giannone and Reichlin (2010), using more than 100 variables, showed that the Minnesota prior leads to improved forecasting performance compared to factor models. In general, the Minnesota prior, which assumes a multivariate normal distribution, is superior to the Normal-Wishart prior $^{5}$ (Koop and Korobolis 2009). Using Doan et al.’s (1984) formula for the uncertainty of the Minnesota prior means, we can specify individual prior variances for a large number of coefficients in the model using only a few parameters (LeSage 1999). These parameters $\theta, \phi$ and $w(i, j)$ represent the overall tightness, lag decay and the weighting matrix respectively. We estimate the BVAR model through the "mixed estimation" technique developed by Theil and Goldberger (1961). This method involves supplementing data with prior information on the distributions of the coefficients (Ramos 2003). A typical unrestricted VAR with $\mathrm{n}$ endogenous variables and $p$ lags can be written as:

\footnotetext{
${ }^{5}$ First, it greatly reduces the computational burden because it does not require MCMC methods. Rather, it leads to simple analytical results for the posterior and there is no need to use computationally demanding posterior simulation algorithms such as the Gibbs sampler. Second, it enables a wide flexibility when determining the prior.
} 


$$
y_{i t}=\sum_{k=1}^{p} a_{i 1 k} y_{1, t-k}+\cdots+\sum_{k=1}^{p} a_{i n k} y_{n, t-k}+\varepsilon_{i t}
$$

Focusing on a single equation of the model:

$$
y_{1}=X A+\varepsilon_{1}
$$

where $\mathrm{y}_{1}$ is the vector of observations on $y_{i t}$, the matrix $\mathrm{X}$ represent the lagged values of $y_{i t}, i=1, \ldots, n$ and the deterministic components, the vector A stands for the coefficients of the lagged variables and deterministic components and $\varepsilon_{1}$ is the residual vector. Prior restrictions for this single equation model can be written as:

$$
\left[\begin{array}{c}
z_{111} \\
z_{112} \\
\vdots \\
z_{n n k}
\end{array}\right]=\left[\begin{array}{cccc}
\sigma / \sigma_{111} & 0 & \cdots & 0 \\
0 & \sigma / \sigma_{112} & \cdots & 0 \\
\vdots & \vdots & \ddots & \vdots \\
0 & 0 & \cdots & \sigma / \sigma_{n n k}
\end{array}\right]\left[\begin{array}{c}
a_{111} \\
a_{112} \\
\vdots \\
a_{n n k}
\end{array}\right]+\left[\begin{array}{c}
v_{111} \\
v_{112} \\
\vdots \\
v_{n n k}
\end{array}\right]
$$

Here $z_{i j k}$ is the prior mean and $\sigma_{i j k}$ is the standard deviation of the Minnesota prior imposed on variable $j$ in equation $i$ at lag $k$, and $\operatorname{var}(v)=\sigma^{2} I$. The standard deviation defined by the Minnesota prior is as follows:

$$
\sigma_{i j k}=\left\{\begin{array}{cl}
\frac{\theta}{k^{-\phi}} & \text { if } i=j \\
\frac{\theta \cdot w}{k^{-\phi}} *\left(\frac{\widehat{\sigma}_{j}^{u}}{\widehat{\sigma}_{i}^{u}}\right) & \text { if } i \neq j
\end{array}\right.
$$

where $\theta$ represents the tightness of the prior. It shows the standard deviation of the prior on the first lag of the dependent variable. A higher tightness implies that less influence of the lagged dependent variable in each equation. The parameter $\phi$ stands for the decay parameter taking the value between 0 and 1 . The decay parameter reflects the fact that standard deviation of the prior decreases as the lag length of the model increases. This implies that further lags have less importance in the model. The parameter $w$ specifies the relative tightness for variables other than the dependent variables. The parameter $\sigma_{j}^{u}$ is 
the standard error of the residuals obtained from the estimation of unrestricted singleequation autoregression on variable $j$. The ratio of the standard errors in Eq. (4) is called a scaling factor and accounts for the differences in the magnitudes of the variables across equations $i$ and $j$.

In order to find the optimum values for the parameters $\theta, \phi$ and $w$, we minimize the log determinant of the sample covariance matrix of the one-step-ahead forecast errors for all the equations of the BVAR (Doan et al. 1984). Using Theil and Goldberger (1961), we rewrite equation (3) as:

$$
r=R A+v
$$

Then, the estimator for a typical equation is:

$$
\hat{A}=\left(X^{\prime} X+R^{\prime} R\right)^{-1}\left(X^{\prime} y_{1}+R^{\prime} r\right)
$$

We estimate a separate BVAR model for each brand, with its performance variable and the available online and offline marketing actions (see table 2) as endogenous variables. Given the high number of potential interactions, we include such interactions one by one and only retain those with significant performance effects. The appendix A1 details each of the five steps of BVAR modeling. After uncovering the estimates and finding the bootstrapped standard errors, we assess whether each generalized impulse-response (GIR) value is significantly different from zero as in previous VAR- literature (e.g. Sims and Zha 1995, Pauwels, Hanssens and Siddarth 2002, Pauwels et al. 2004). We sum up all significant GIR values to obtain the cumulative effect of each marketing variable on performance. 


\section{DATA AND OPERATIONALIZATION}

Assessing our hypotheses on long-term marketing elasticities and synergies requires time-series data with at least 50 weekly observations (see Hanssens et al. 2001) of brand performance and several online and offline media types. We were able to obtain such data for brands from four companies across a variety of settings that substantially differ on the relevant dimension of brand familiarity.

Brand A was launched less than 5 years before the data period, in the market for scholastic test preparation. Using adaptive learning software, this company provides flexible individual-level customization for scholastic test preparation. The absence of fixed overhead costs due to no brick-and-mortar presence enables the company to price competitively in the market. However, its business model represents a departure from the traditional face-to-face interaction prevalent in this category. To communicate this positioning, Brand A therefore uses a variety of online marketing efforts such as display ads and paid search. During the global recession, the company communicated to prospective customers that it would vary its price with stock market indices. Such communicated price changes are the main firm-initiated actions by brand A.

Brand B is a family-run office furniture supplier without retail stores, they market furniture directly to offices, hospitals, schools and individuals. Firm-initiated marketing actions constitute the major part of its marketing budget and include direct mail and faxes sent directly to prospective customers. Online marketing actions include email and paid search. Brand B focuses on its product quality and delivery to the customer, assembly of furniture, and customized furniture solutions. 
Brand C is a top-five travel brand (Harris Interactive 2012). It provides travelrelated services to its customers for flights, hotels and cars. The company initiated its marketing efforts with online communication but soon switched the budget to mostly offline communication, including global television advertising campaigns. Marketing communication actions include paid search, display, partner site links, television and outof-home advertising.

Brand D is a US apparel retail brand that was in the top 30 of Interbrand Best Retail Brands 2013. Brand D’s products are targeted at the mass market with a focus on casual apparel for men and women. The brand's advertising is prominent and extensive, and is present on multiple channels such as television, radio, print, and online paid search. Store traffic is the main performance indicator for this retailer.

To verify third-party brand familiarity judgments, we assessed unaided and aided brand awareness via survey respondents on Amazon's Mechanical Turk. ${ }^{6}$ Our first four survey questions (one per category) asked respondents to name three brands in the category (unaided awareness). The next four questions inserted the studied brand name and logo in random order among two known brands in the category, and asked respondents which brands they recognized (aided awareness). The results reveal that nobody spontaneously mentioned the scholastic test preparation service brand A as well as office furniture brand $\mathrm{B}$. In contrast, the travel website service brand $\mathrm{C}$ was mentioned by 18 respondents $(11 \%)$ as their first answer, by $21(13 \%)$ as the second answer and by

\footnotetext{
${ }^{6}$ Mturk is an online crowdsourcing system for recruiting survey respondents. Buhrmester, Kwang and Gosling (2011) showed that Mturk enables researchers to obtain high-quality data inexpensively and rapidly. The authors note that participants are more diverse than standard Internet or student samples and the data obtained is at least as reliable as the data obtained by traditional methods. Our survey was open for two weeks during May 2014, resulting in a total of 166 respondents and 160 usable answers.
} 
$22(14 \%)$ as the third answer. Apparel retail brand D was mentioned by $7(4.4 \%)$ respondents as their first answer, by $16(10 \%)$ as their second answer and by $10(6.3 \%)$ respondents as their third answer. As for aided awareness, $3 \%$ of respondents recognized brand $\mathrm{A}, 3 \%$ recognized brand $\mathrm{B}, 76 \%$ recognized brand $\mathrm{C}$ and $96 \%$ recognized brand $\mathrm{D}$. Thus, our survey sample shows unaided (aided) awareness of 0\% (3\%) for both brands A and $\mathrm{B}, 38 \%(76 \%)$ for brand $\mathrm{C}$ and $21 \%(96 \%)$ for brand $\mathrm{D}$. Using these survey results as well as the absence versus presence of the brands on the top-brands lists of Harris Poll Equitrend Study and Interbrand, we conclude that brands A and B are relatively unfamiliar, while brands $\mathrm{C}$ and $\mathrm{D}$ are relatively familiar to consumers.

All datasets are at the weekly level for a recent period of over a year. Brand A's data spans 2008 (week 40) to 2010 (week 8), with a total of 73 observations. Brand B's data spans 2007 (week 1) to 2010 (week 35), with 191 observations. Brand C's data spans 2008 (week 1) to 2010 (week 35), with a total of 139 observations. Finally, Brand D’s data spans 2010 (week 25) to 2011 (week 28), with 55 observations.

Data from all companies include the variables on online (customer-initiated) media such as site visits and paid search, offline (firm-initiated) media and a performance variable. Table 2 displays the variable operationalization.

--- Insert Table 2 about here ---

Our classification of each marketing action into customer-initiated (online) and firminitiated (offline) follows the definitions in our conceptual framework. Note that email is a firm-initiated marketing action, because companies can increase spending on emails without any prospective customer action. In contrast, our studied brands only pay for 
display ads when a prospective customer clicks on them. Some online media are identical among firms (e.g., paid search cost) while others are not (e.g., total website visits versus only organic website visits). Likewise, the offline marketing actions differ by firm. This is typical when moving from single-firm to multi-firm evidence; to the best of our knowledge there is not yet a standardized dataset for online media (as e.g., the scanner panel data for price, feature and display). To control for seasonality, we include fourweekly seasonal dummies for brands A-C, using January as our benchmark. For brand D, we use the national retail mall index, which offers weekly tracking of overall U.S. retail mall sales. As can be seen in Table 3, weekly average sales revenues for unfamiliar brands A and B are below $\$ 260,000$. In contrast, weekly average sales revenues of the familiar brands C and D are above $\$ 900,000$. Table 3 shows summary statistics for the variables included in the model.

--- Insert Table 3 about here ---

In light of the differences across firms in the data (Table 3), the log-log specification helps with obtaining elasticity estimates, facilitating comparisons across brands.

\section{EMPIRICAL FINDINGS}

For each analyzed brand, both the AIC and SIC information criteria point to the inclusion of one lag in the log-log model. The estimated models perform well in terms of explanatory power, explaining $78 \%$ to $91 \%$ (adjusted $\mathrm{R}^{2}=76 \%$ to $90 \%$ ) of the variation in the performance variables. As to out-of-sample forecasting, we set aside the last $20 \%$ of each brand's time series to calculate the Mean Average Percentage Error (MAPE) for the 
1-step ahead and the h-step ahead forecasts (with $\mathrm{h}$ the maximum number of hold-out weeks).

--- Insert Table 4 about here ---

While forecast errors are, as expected, larger for forecasts further in the future, the highest MAPE remains below $18.5 \%$, which indicates the high explanatory power of our models is not due to overfitting. Moreover, the models show no violation of the autocorrelation, heteroscedasticity, and normality assumptions for the residuals (Franses 2005), nor indicate omitted variable bias (Stock and Watson, 2003) ${ }^{7}$. We next discuss the long-term elasticity estimates of marketing actions in the main-effects only models, followed by an assessment of synergy, as a test of our proposed hypotheses.

\section{Long-term elasticity of marketing actions (main effects models)}

From the GIRFs, we obtain the total (cumulative) elasticity of each marketing action on brand performance, as shown in Table 5 for the main effects BVAR model.

--- Insert Table 5 about here ---

For each brand, the cumulative elasticity results show a substantially higher performance impact for online customer-initiated media than for offline firm-initiated media, consistent with previous literature (e.g. De Haan, Wiesel and Pauwels 2013; Dinner, van Heerde and Neslin 2014; Wiesel, Pauwels and Arts 2011). Within online, each brand shows the highest elasticity for prospective consumers coming to the owned site (i.e. owned media): direct and organic site visits for brand A, site visits for brand B,

\footnotetext{
${ }^{7}$ Ramsey RESET test tests the null hypothesis that the model has no omitted variable bias. The test results, available upon request, fail to reject that null hypothesis.
} 
organic Google traffic and organic site visits for brand C, and organic Google search for brand D. Among paid media, each brand shows the highest elasticity is for paid search. To verify the robustness of our results, we also estimate the equivalent main effects single-equation OLS model. ${ }^{8}$ Table 5 also shows the results, which are similar to the BVAR findings in both sign and significance of the main effects. These results are as expected since the main effects model has a relatively low number of parameters, enabling OLS to be rather efficient.

What do these cumulative elasticities imply for marketing budget allocation? In the absence of synergy, companies would be advised to spend a larger portion of the communication budget on online media which have a larger elasticity than offline media (Naik and Raman 2003). This is reflected in company practice of setting upper limits to online advertising bids by multiplying the short-term conversion probability with margin earned per conversion (Dinner et al. 2014). However, this does not account for either long-term effects or synergy. Patterns in these effects allow us to assess our hypotheses on within-channel versus cross-channel synergy.

\section{Assessment of Synergy in Online and Offline Media}

When we add interaction effects to our models, the results change as shown in table 6 .

\section{----- Insert Table 6 around here ----}

From the BVAR results, we observe that synergy is present for each brand, as several of the interactions are significant and often substantial compared to the main

\footnotetext{
${ }^{8}$ To avoid multicollinearity, we log centered the variables in the OLS estimation..
} 
effects. The single-equation OLS results show a similar pattern. For brands A and C, the sign and significance of the parameters are the same. However, the OLS results show less significant interaction terms for brands $\mathrm{B}$ and $\mathrm{D}$, which is likely due to the high number of parameters. We infer that OLS estimation is less efficient because it does not impose any stochastic constraints on the estimated parameters as opposed to the BVAR model.

In testing our hypotheses, we compare the within-channel versus cross-channel synergy effects in two ways. First, we consider the synergy with the median effect (across all actions for that synergy type) and the synergy with the highest estimated effect for that synergy type (hereafter 'best in breed'). This allows us to assess the hypotheses on both of these benchmarks. Specifically, based on the GIRF estimates, for each brand we conduct a two- tailed t-test to test our hypotheses for (i) the 'typical' (median elasticity) action for each synergy type, and (ii) the best-in-breed (highest elasticity) action for each synergy type.

Table 7 provides these results. The panel on the left corresponds to the tests for the typical synergy while the panel on the right corresponds to the test for the best-in-breed synergy. Within each panel, the synergy type (within-online and cross-channel), and the corresponding median or maximum are listed in the first and second columns, respectively. The hypothesis tested is in the third column while the final column in each panel gives the outcome of the t-test. For example, unfamiliar brand A experiences an elasticity of 0.374 for median ('typical') cross-channel synergy and 0.428 for maximum (best-in-breed) crosschannel synergy. These numbers come from the cumulative effect of price*organic visits (0.374 in table 7$)$ and price*direct visits (0.428 in table 7$)$, with price*paid search $(0.069$ in table 7) is the lowest elasticity for cross-channel synergy. 
We first report the median ('typical' action) results. We compare the cross synergy between online and offline media with the within-online synergy, focusing on the unfamiliar brands A and B. As seen from Table 5, cross synergy is higher than withinonline synergy for both unfamiliar brands A and B ( 0.374 vs. 0.072 with $p<.1$ and 0.044 vs. 0.004 with $p>.1$, respectively). Based on the best-in-breed results, the same finding holds, i.e. cross synergy is higher than within-online synergy $(0.428$ vs. 0.250 with $p>.1$ for brand A and 0.554 vs. 0.004 with $p<.01$ for brand B).

For familiar brands for the typical action results, within-online synergy is higher than cross-synergy for both brands $\mathrm{C}$ and $\mathrm{D}(0.451$ vs. 0.003 with $p<.01$ and 0.213 vs. 0.003 with $p<.01$, respectively). The same finding holds for the 'best-in-breed' results (0.451 vs 0.006 with $p<.01$ for brand $\mathrm{C}$ and 0.336 vs. 0.004 with $p<.01$ for brand $\mathrm{D}$ ).

\section{Implications}

Our framework and empirical results shed light on a number of important implications in understanding the potential benefits of synergy in different online advertising media. The results show that 'within online synergy' is significantly higher than 'cross channel synergy' for familiar brands in our data, which may mean that, high and favorable awareness has already been created in offline media for well-known brands. An alternative explanation may be that familiar brands are more likely to spend near-optimally while unfamiliar brands spend far below optimal, which leads to higher returns from increasing spending. ${ }^{9}$ However, this would not explain why familiar brands have higher within-online synergy. Moreover,

\footnotetext{
${ }^{9}$ We thank the Associate Editor and an anonymous reviewer to bring this to our attention.
} 
this explanation would require systematic differences in spending effectiveness for familiar versus unfamiliar brands - which we do not observe in the results tables.

We also find that owned media has a higher sales elasticity than paid media for unfamiliar brands and for the familiar service brand. Thus, owned media is a credible source for consumers to decrease the unpredictable nature of services and of unfamiliar brands. By contrast, we find that sales elasticity of paid media is higher than owned media for familiar product brand. In the latter instance, paid media can provide enough information with which to evaluate the quality and enables the firm to maximize reach for familiar products.

Finally, how do our results relate to the recent findings that (certain types of) paid media are not effective in lifting sales for a well-known hospitality brand (Li and Kannan 2014) but effective in lifting sales for a relatively unknown furniture brand (Wiesel et al.2011)? First, the company studied in Li and Kannan (2014) is similar to our brand C, and they too find a low sales impact for paid media and a large within-online 'spillover' (synergy). Our research implies that such findings do not generalize to unfamiliar brands, thus confirming Li and Kannan's (2014) speculation that unfamiliar brands face a different marketing type effectiveness challenge. Second, while Wiesel et al. (2011) study the same brand as our brand B and report a strong effect of paid search, they do not incorporate synergy, and thus miss an important part of picture (Li and Kannan 2014). We show this next by calculating optimal allocation recommendations with synergy versus without synergy (i.e. the main effects model of table 5). 


\section{Marketing Budget Allocation Optimization}

Our empirical estimation yields marketing spending elasticities that managers can use to optimize their marketing budget allocation under the usual caveats that the model specification captures the major drivers of sales and that the near future is similar to the past. We illustrate the importance of synergy using this procedure, we present the allocation optimization for unfamiliar brand B analyzed by Wiesel et al. (2011) in a model without synergy.

From the log-log BVAR model, we derive the marketing-sales elasticities as the total over-time impact captured by the Generalized Impulse Response Functions. For the main effects model, each marketing action is allocated a budget corresponding to its elasticity compared to the elasticity of the other marketing actions (Dorfman and Steiner 1954; Wright 2009). For the synergies model, the marginal elasticity of marketing action X1 depends on the level of the other marketing action X2. Assuming the level of X2 is fixed at the mean values of the variables, we combine the main effect and the interaction effect for X1's elasticity (Naik and Raman 2003, see appendix A2 for details). Figure 1 contrasts the current allocation, the optimal allocation from the BVAR model without synergy, and the optimal allocation from the BVAR model with synergies.

---- Insert Figure 1 about here ----

Due to the high relative elasticity of online paid search, the main effects BVAR model implies that brand B should increase its paid search spending from $18 \%$ to $91 \%$ of its budget, dropping its main marketing activity, direct mail, from $66 \%$ to $6 \%$. Catalogs are found to be ineffective, and thus should be set to $0 \%$ in the optimal allocation while fax spending should remain at its current level. This reallocation is similar to the one implied in 
Wiesel et al. (2011). However, the offline actions of direct mail and fax have strong synergies with online search, and the allocation that accounts for these synergies (the right

column in Figure 1) suggests a more balanced budget. Online paid search receives $44.5 \%$, while direct mail receives $36.9 \%$ and fax $18.6 \%$. We also calculate the confidence bounds to account for the uncertainty in these allocations, as shown in Table 8.

---- Insert Table 8 about here ----

Overall, the findings suggest that online paid search and direct mail work synergistically in conjunction with faxes in driving sales for brand B. Accounting for synergies among marketing actions can thus lead to substantially different optimal marketing resource allocation.

\section{CONCLUSIONS, LIMITATIONS AND FUTURE RESEARCH}

In this study, we provide a conceptual framework on cross-channel and infra-channel synergies by taking into consideration brand familiarity. We propose that unfamiliar brands have to build brand equity in multiple channels, and cannot simply leverage existing brand equity online. For unfamiliar brands, the combination of offline and online marketing (cross-synergy) matters more than intra-channel synergy. Familiar brands, on the other hand, are better able to leverage their brand equity online since consumer knowledge is already high to begin with.

We illustrate the framework's applicability for two familiar and two unfamiliar brands. The empirical results obtained from BVAR estimations showed that within-online synergy is significantly higher than cross-channel synergy for the studied familiar brands, while unfamiliar brands experience higher synergy of online media with offline 
marketing, which implies they should spend more on offline media than implied by their low direct sales elasticity. This paper is the first to show cross-channel synergies of online media with direct mail (brand B) and with radio (brand D). Consistent with previous results, we also find synergy among TV and online media for every analyzed brand that invested in TV ads (Chang and Thorson 2004). As developed in Raman and Naik (2004), synergy effects imply that any medium deserves a non-zero budget despite its limited or unknown effectiveness. The high within-online synergy for familiar brands also provides a boundary condition for the advice that "Once a brand is familiar; expenses can be curtailed by reducing the number and types of media" (Stammerjohan et al. 2005; p.65).

Our results have important implications for marketing theory. First of all, our results add to online media research by addressing how effectiveness varies with brand familiarity. Second, although research on synergy is growing, the conditions for synergy (just as brand-related effects and the use of social media) are still mostly neglected. Our study demonstrates the importance of incorporating brand familiarity into models for integrated marketing communications (Winer 2009). Furthermore, it addresses the need for new methods and approaches going beyond offline media forms by incorporating new developments on online media.

Our work has also important implications for marketing practitioners. First, managers of unfamiliar brands may obtain substantial synergy from offline marketing spending, even though its direct elasticity pales in comparison with that of online media. Second, our results show that managers of familiar brands can generate more synergy by investing in different online media, thus confirming the opening quote by Green (2012). 
Our study is not free of limitations. The use of data of two unknown and two known brands limit the generalizability of our results. However, the aim of this study is to obtain insights on the effectiveness of especially new advertising formats for different conditions rather than offering empirical generalizations (EGs). Future research should offer EGs on this topic. Additionally, the selection of variables is limited to their availability in the data sets - omitted variables include the focal brand's quality changes and new product introductions, competitive communication spending and market environment factors. Specifically relevant for the purpose of this paper, we had different offline and online advertising types across brands. Future research should define metrics that are most appropriate for earned, owned or paid media measurement. Defining and proposing metrics for new advertising formats is an important need in the area. As typical in budget allocation across media, we have assumed that the studied brands tactically execute their communication in a similarly competent manner (and therefore that substantially lower effectiveness of a medium is not simply due to its poor execution). Future research may test this assumption. In addition, it would be useful to investigate how our results on the impact of brand familiarity on media synergy vary over the product life cycle. Furthermore, practitioners, data providers and academics should collaborate to explore the possibility of standardized datasets for paid, owned, earned media (as e.g., scanner panel data for price, feature and display), which represents both a challenge and an opportunity. We also identify an opportunity for future research on the methods used. In our BVAR modeling with a Minnesota prior, we assume that the offdiagonal elements in the prior variance-covariance matrix are zero to simplify 
computation. Future research can allow for more flexible variance-covariance matrix using more complex estimations based on MCMC methods.

Another research area is to understand the differentiated effect of various online advertising mediums along the different stages of consumer decision-making. The interplay between different online advertising formats and effects of brand familiarity or product-service dichotomy may vary through these different stages of consumer decision making. Additionally, we show a greater sales elasticity for 'within-online synergy' for familiar brands. However, the results are mixed for unfamiliar brands. This area may need additional investigation.

In summary, our research is the first to conceptually and empirically investigate how brand-familiarity impacts online media synergy as well as online and offline media synergy. We believe this work puts recent single-firm findings into perspective and we hope to inspire further research towards empirical generalizations on the effectiveness of new and established media. 


\section{REFERENCES}

Anand, Punam and Brian Sternthal (1990), "Ease of Message Processing as a Moderator of Repetition Effects in Advertising," Journal of Marketing Research, 27 (August), 345-353.

Animesh, Animesh, Vandana Ramachandran, and Siva Viswanathan (2010), "Quality Uncertainty and the Performance of Online Sponsored Search Markets: An Empirical Investigation," Information Systems Research, 21 (1), 190-201.

Banbura, Marta, Domenico Giannone, and Lucrezia Reichlin (2010), "Large Bayesian Vector Auto Regressions," Journal of Applied Econometrics, 25, 71-92.

Baskin, Jonathan S. (2011), "Do Campaign Failures, High-Profile Firings Signal the End of Social Media?," (accessed March 22, 2011), [available at http://adage.com/article/cmo-strategy/pepsiburger-king-news-signal-end-social-media/149523/].

Blake, Thomas, Chris Nosko, and Steven Tadelis (2013), "Consumer Heterogeneity and Paid Search Effectiveness: A Large Scale Field Experiment,” Econometrica, 83(1), 155-174.

Bowman, Douglas and Das Narayandas (2001), "Managing Customer-Initiated Contacts with Manufacturers: The Impact on Share of Category Requirements and Word-of-Mouth Behavior," Journal of Marketing Research, 281-297.

Buhrmester, Michael, Tracy Kwang, and Samuel D. Gosling (2011). Amazon's Mechanical Turk: A New Source of Inexpensive, Yet High-Quality, Data? Perspectives on Psychological Science, 6(1), $3-5$.

Bustos, Linda (2008), “The Forgotten Metric: Direct Traffic Reveals Brand Strength,” (accessed July 31, 2009), [available at http://www.getelastic.com/direct-traffic-google-analytics/].

Cacioppo, John T. and Richard E. Petty (1979), "Effects of Message Repetition and Position on Cognitive Response, Recall, and Persuasion," Journal of Personality and Social Psychology, 37(1), 97.

Campbell, Margaret C. and Kevin Lane Keller (2003), "Brand Familiarity and Advertising Repetition Effects," Journal of Consumer Research, 30(September), 292-304.

Chang, Yuhmiin and Esther Thorson (2004), "Television and Web Advertising Synergies," Journal of Advertising, 33 (2), 75-84.

Ciccarelli, Matteo and Alessandro Rebucci (2003), "Bayesian VARs: A Survey of the Recent Literature with an application to the European Monetary System," Working Paper No. 03/102, International Monetary Fund.

CMO Survey (2013), “CMOs on Social Media: Where's the ROI?," (accessed May 1, 2015) [at http://www.forbes.com/sites/dorieclark/2013/09/12/cmos-on-social-media-wheres-the-roi/].

Corcoran, Sean (2009), "Defining Earned, Owned and Paid Media,", (accessed May 1, 2015), [available at http://blogs.forrester.com/interactive_marketing/2009/12/defining-earned-owned-andpaid-media.html]. 
Danaher, Peter J. and Tracey S. Dagger (2013), "Comparing the Relative Effectiveness of Advertising Channels: A case Study of a Multimedia Blitz Campaign," Journal of Marketing, 50 (August), 517-534.

De Haan, Evert D., Thorsten Wiesel, and Koen Pauwels (2013), "Which Advertising Forms Make a Difference in Online Path to Purchase?" Working Paper Series No. 13, Marketing Science Institute.

Dijkstra, Majorie, Heidi E.J.J.M. Buijtels, and W. Fred Van Raaij (2005), "Separate and Joint Effects of Medium Type on Consumer Responses: A Comparison of Television, Print, and the Internet," Journal of Business Research, 58, 377-386.

Dinner, Isaac. M., Harald J. Van Heerde, and Scott Neslin (2014), "Driving Online and Offline Sales: The Cross-channel Effects of Digital versus Traditional Advertising," Journal of Marketing Research, 51 (5), 527-545

Doan, Thomas, Robert B. Litterman, and Christopher A. Sims (1984), "Forecasting and Conditional Projection Using Realistic Prior Distributions," Econometric Reviews, 3, 1-100.

Dorfman, Robert and Peter O. Steiner (1954), "Optimal Advertising and Optimal Quality," The American Economic Review, 44 (5), 826-836.

Edell, Julie A. and Kevin L. Keller (1989), "The Information Processing of Coordinated Media Campaigns," Journal of Marketing Research, 26 (May), 149-63.

EMarketer (2013), "Worldwide Ad Growth Buoyed by Digital, Mobile Adoption," (accessed July 21, 2013), [available at http://www.emarketer.com/Article/Worldwide-Ad-Growth-Buoyed-byDigital-Mobile-Adoption/1010244].

Foresee Results (2011), "Social Media Marketing: Do Retail Results Justify Investment," (accessed September $\left.15^{\text {th }}, 2014\right)$, [available at http://www.scribd.com/doc/204504338/Social-MediaMarketing-u-s-2011-Foresee.]

Franses, Philip H. (2005), "On the Use of Econometric Models for Policy Simulation in Marketing," Journal of Marketing Research, 42(1), 1-14.

Gallaugher, John M., Pat Auger, and Anat Barnir (2001), "Revenue Streams and Digital Content Providers: An Empirical Investigation," Information and Management, 38 (7), 473-485.

Gartner, Inc (2008), "A Checklist for Evaluating an Inbound and Outbound Multichannel Campaign Management Application," (accessed September, 2010), [available at https://www.gartner.com/doc/750252/checklist-evaluating-inbound-outbound-multichannel]

Godes, David and Dina Mayzlin (2004), "Using Online Conversations to Study Word-of-Mouth Communication," Marketing Science, 23(4), 545-560.

Green, Alistair (2012), "Paid, Owned and Earned Media: Integration's Holy Grail,” (accessed September 13, 2014), [available at http://www.greatmediaminds.net/2012/05/31/paid-owned-andearned-media-integrations-holy-grail/].

Hanssens, Dominique M. (2009), Empirical Generalizations about Marketing Impact: What We Have Learned from Academic Research. Cambridge: Marketing Science Institute. 
Leonard J. Parsons, and Randall L. Schultz (2001), Market Response Models: Econometric and Time Series Analysis. 2nd Edition, Kluwer Academic Publishers.

Harris Interactive (2012)," (accessed September 16, 2014, 2014), [available at http://www.prnewswire.com/news-releases/top-ranked-travel-brands-southwest-kayak-royalcaribbean-and-enterprise-continue-to-rule-the-industry-as-brands-of-the-year-according-to-the-23rdannual-harris-poll-equitrend-study-146794695.htmll.

Hoffman, Donna L. and Thomas P. Novak (2000), "How to Acquire Customers on the Web," Harvard Business Review. May-June, 78 (3), 179-183.

and Marek Fodor (2010), "Can You Measure the ROI of Your Social Media Marketing?," MIT Sloan Management Review, 52 (1), 41-49.

Horvath, Csilla and Dennis Fok (2013), "Moderating Factors of Immediate, Gross, and Net CrossBrand Effects of Price Promotions," Marketing Science, 32 (1), 127-152.

Ilfeld, Johanna S. and Russell S. Winer (2002), "Generating Website Traffic," Journal of Advertising Research, 42 (5), 49-61.

Kadiyala, K. Rao and Sune Karlsson (1997) "Numerical Methods for Estimation and Inference in a Bayesian VAR-Models," Journal of Applied Econometrics, 12, 99-132.

Kahneman, Daniel (1973), Attention and Effort. New Jersey: Prentice Hall, Englewood Cliffs.

Keller, Kevin L. (1993), "Conceptualizing, Measuring and Managing Customer-based Brand Equity,” Journal of Marketing, 57(1), 1-22.

Kireyev, Pavel, Koen Pauwels, and Sunil Gupta (2013), "Do Display Ads Influence Search? Attribution and Dynamics in Online Advertising," Working Paper No. 13-070, Harvard Business School.

Koop, Gary and Dimitris Korobilis (2009), "Bayesian Multivariate Time Series Methods for Empirical Macroeconomics," Foundations and Trends in Econometrics, 3 (4), 267-358.

LeSage, James P. (1999), “Applied Econometrics Using Matlab,” (accessed September 7, 2010), [available at http://www.spatial-econometrics.com/html/mbook.pdf].

LeSage, James P. and Anna Krivelova (1999), "A Spatial Prior for Bayesian Vector Autoregressive Models,” Journal of Regional Science, 39(2), 297-317.

Li, Hongshuang, and P. K. Kannan (2014), 'Attributing Conversions in a Multichannel Online Marketing Environment: An Empirical Model and a Field Experiment," Journal of Marketing Research 51 (1), 40-56.

Lieb, Rebecca and Jeremiah Owyang (2012), "The Converged Media Imperative: How Brands must combine Paid, Owned and Earned Media", Altimeter Report, July 18, accessed December 13, 2014: http://www.slideshare.net/Altimeter/the-converged-media-imperative.

Litterman, Robert B. (1986), "Forecasting with Bayesian Vector Autoregressions: Five years of Eexperience," Journal of Business and Economic Statistics, 4, 25-38. 
MacInnis, Deborah J. and Bernard J. Jaworski (1989), "Information Processing from Advertisements: Toward an Integrative Framework," Journal of Marketing, 53 (October), 1-23.

Manchanda, Puneet, Jean-Pierre Dube, Khim Y. Goh, and Pradeep K. Chintagunta (2006), "The Effect of Banner Advertising on Internet Purchasing," Journal of Marketing Research, 43 (1), 98108.

McGovern, Gail and John A. Quelch (2007), Measuring Marketing Performance. Harvard Business School Multimedia Tool.

Moe, Wendy W. and Michael Trusov (2011), "The Value of Social Dynamics in Online Product Ratings Forums, Journal of Marketing Research, 48(3) 444-456.

Naik, Prasad A. and Kay Peters (2009), "A Hierarchical Marketing Communications Model of Online and Offline Media Synergies,” Journal of Interactive Marketing, 23 (4), 288-299.

and Kalyan Raman (2003), "Understanding the Impact of Synergy in Multimedia Communications," Journal of Marketing Research, 40 (4), 375-88.

Pauwels, Koen, Dominique M. Hanssens, and S. Siddarth (2002), "The Long-term Effects of Price Promotions on Category Incidence, Brand Choice, and Purchase Quantity," Journal of Marketing Research, 39 (4), 421-439.

— Jorge Silva-Risso, Shuba Srinivasan, and Dominique M. Hanssens (2004), "New Products, Sales Promotions, and Firm Value: The Case of the Automobile Industry. Journal of Marketing, 68 (October), 142-56.

Pesaran, H. Hashem and Yongcheol Shin (1998), "Generalized Impulse Response Analysis in Linear Multivariate Models," Economic Letters, 58 (1), 17-29.

Pfeiffer, Markus and Markus Zinnbauer (2010), "Can Old Media Enhance New Media? How Traditional Advertising Pays off for an Online Social Network," Journal of Advertising Research, 50(1), 42-49.

Raman, Kalyan and Prasad A. Naik (2004), "Long-term Profit Impact of Integrated Marketing Communications Program,” Review of Marketing Science, 2 (1), 21-23.

Ramos, Riberio F. F. (2003), "Forecasts of Market Shares from VAR and BVAR Models: A Comparison of Their Accuracy," International Journal of Forecasting, 19, 95-110.

Reimer, Kerstin, Oliver J. Rutz, and Koen Pauwels (2014), "How Online Consumer Segments Differ in Long-term Marketing Effectiveness," Journal of Interactive Marketing, 28(4), 271-284.

Schultz, Don E., Martin P. Block, and Kaylan Raman (2012), "Understanding Consumer-created Media Synergy," Journal of Marketing Communications, 18 (3), 173-187.

Sims, Christopher A., James H. Stock, and Mark W. Watson (1990), "Inference in Linear Time Series Models with Some Unit Roots," Econometrica, 58 (1), 113-144. and Tao Zha (1998), "Bayesian Methods for Dynamic Multivariate Models," International Economic Review, 39 (4), 949-968. 
Sonnier, Garrett P., Leigh McAlister and Oliver J. Rutz (2011), "A Dynamic Model of the Effect of Online Communications on Firm Sales,” Marketing Science, 30(4), 702-716.

Stammerjohan, Claire, Charles M. Wood, Yuhmiin Chang, and Esther Thorson (2005), “An Empirical Investigation of the Interaction between Publicity, Advertising, and Previous Brand Attitudes and Knowledge. Journal of Advertising, 34 (4), 55-67.

Stock James H. and Mark W. Watson (2003). Introduction to Econometrics. New York: Prentice Hall.

Theil, Henri and Arthur S. Goldberger (1961), "On Pure and Mixed Statistical Estimation in Economics," International Economic Review, 2, 65-78.

Trusov, Michael, Randolph E. Bucklin and Koen Pauwels (2009), "Effects of Word of Mouth versus Traditional Marketing: Findings for an Internet Social Networking Site," Journal of Marketing, 73 (5), 90-102.

Wegert, Tessa (2015), "Why the New York Times' sponsored content is going toe-to-toe with its editorial", Contently, March 27, (accessed June $4^{\text {th }} 2015$ ), [available at http://contently.com/strategist/2015/03/27/why-the-new-york-times-sponsored-content-is-going-toeto-toe-with-its-editorial/

Wiesel, Thorsten, Koen Pauwels, and Joep Arts (2011), "Marketing's Profit Impact: Quantifying Online and Off-line Funnel Progression," Marketing Science, 32, 229-245.

Winer, Russell S. (2009), "New Communications Approaches in Marketing: Issues and Research Directions," Journal of Interactive Marketing, 23 (2), 108-117.

Wright, Malcolm (2009), "A New Theorem for Optimizing the Advertising Budget," Journal of Advertising Research, 49 (2), 164-169.

Yang, Sha and Anindya Ghose (2010), "Analyzing the Relationship between Organic and Sponsored Search Advertising: Positive, Negative or zero interdependence?" Marketing Science, 29 (4), 602623. 
Figure 1: Marketing budget allocation options for brand $B$

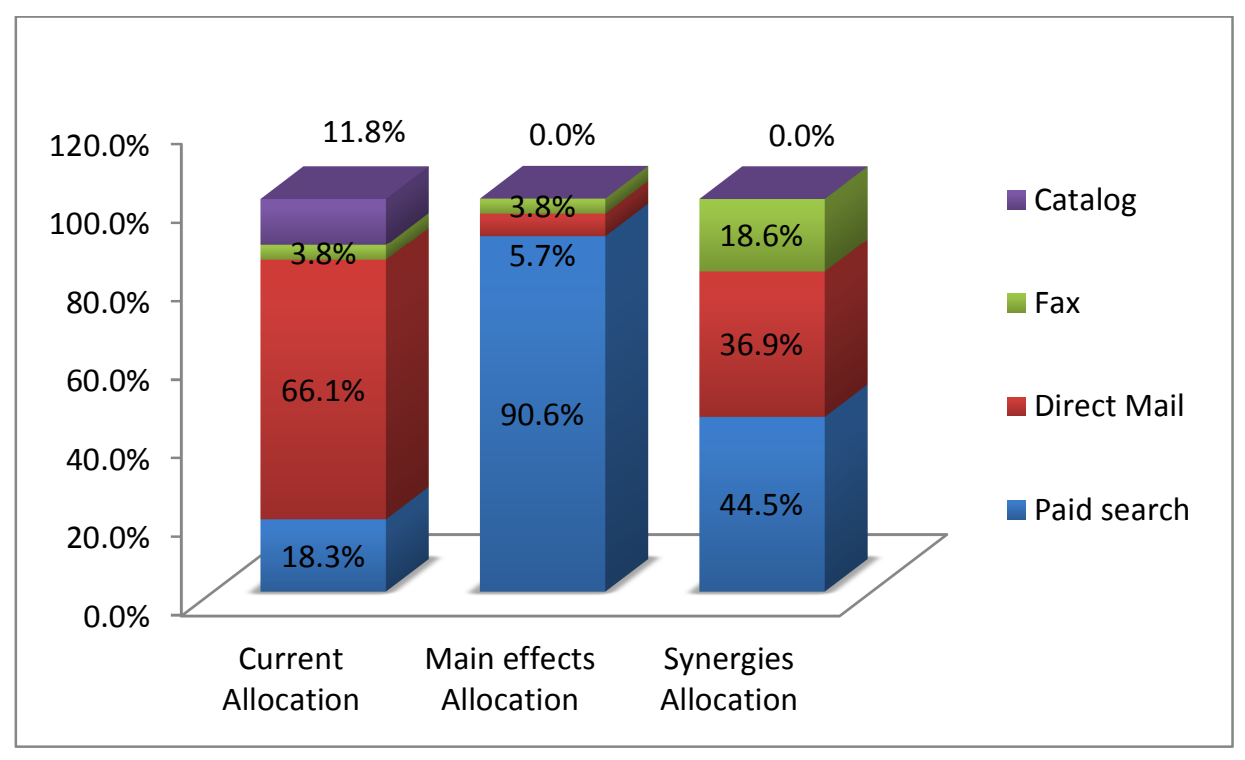


Table 1: Brand Familiarity Conditions and Media Synergy

\begin{tabular}{|c|c|c|}
\hline & & Hypotheses on Synergy \\
\hline \multirow{4}{*}{$\begin{array}{l}\text { Brand } \\
\text { Familiarity }\end{array}$} & \multirow[t]{2}{*}{$\begin{array}{l}\text { Unfamiliar } \\
\text { Brands }\end{array}$} & $\begin{array}{l}\text { For unfamiliar brands, cross-channel synergy is higher } \\
\text { than within-online synergy. }(\mathrm{H} 1)\end{array}$ \\
\hline & & Empirical Cases: Brand A and Brand B \\
\hline & \multirow[t]{2}{*}{$\begin{array}{l}\text { Familiar } \\
\text { Brands }\end{array}$} & $\begin{array}{l}\text { For familiar brands, within-online synergy is higher than } \\
\text { cross-channel synergy. (H2) }\end{array}$ \\
\hline & & Empirical Cases: Brand C and Brand D \\
\hline
\end{tabular}


Table 2: Variable operationalization

\begin{tabular}{|c|c|c|c|}
\hline Firm & Variable & Operationalization & Classification \\
\hline \multirow{7}{*}{ Brand A } & Organic Site Visits & Weekly number of organic visits to the website & Online (CIC) \\
\hline & Paid Search & Weekly cost (per click basis) on Google & Online (CIC) \\
\hline & Amazon Display Ads & Weekly cost (per thousand views) on Amazon display ads & Online (CIC) \\
\hline & US News Display Ads & Weekly cost of a one-page ad in US News & Online (CIC) \\
\hline & Direct Visits & Weekly number of direct visits to the website & Online (CIC) \\
\hline & Price & Weekly average price of an online course & Offline (FIC) \\
\hline & Revenues & Weekly sales revenues & Performance \\
\hline \multirow{8}{*}{ Brand B } & Site Visits & Weekly total visits to the website & Online (CIC) \\
\hline & Paid Search & Weekly cost of (pay-per-click) referrals & Online (CIC) \\
\hline & Direct Mail & Weekly cost of direct mail & Offline (FIC) \\
\hline & Fax & Weekly cost of faxes & Offline (FIC) \\
\hline & Catalog & Weekly cost of catalogs & Offline (FIC) \\
\hline & Discounts & Percentage of revenue given as a discount & Offline (FIC) \\
\hline & eMail & Weekly number of net emails (sent minus bounced back) & Offline (FIC) \\
\hline & Sales revenues & Weekly sales revenues & Performance \\
\hline \multirow{8}{*}{ Brand C } & Organic Site Visits & Weekly site traffic not coming from paid or earned sources & Online (CIC) \\
\hline & Display Ads & Weekly display advertising (e.g. banners) impressions & Online (CIC) \\
\hline & Paid Search & Weekly cost for all search engines used by brand C & Online (CIC) \\
\hline & Search on partners & Weekly other search engines impressions & Online (CIC) \\
\hline & Organic Google traffic & Weekly traffic on Google related to Brand C & Online (CIC) \\
\hline & TV ads & Weekly cost of TV advertising campaigns & Offline (FIC) \\
\hline & Out of home & Weekly out of home advertising impressions & Offline (FIC) \\
\hline & Revenues & Weekly sales revenues & Performance \\
\hline \multirow{9}{*}{ Brand D } & Site Visits & Weekly total number of visits to the website & Online (CIC) \\
\hline & Paid Search & Weekly paid search advertising in impressions & Online (CIC) \\
\hline & Display Ads & Weekly display (e.g. banner) advertising in impressions & Online (CIC) \\
\hline & Earned General & Weekly number of all social media conversations & Online (CIC) \\
\hline & Organic Google search & Weekly index of searches through Google.com & Online (CIC) \\
\hline & TV GRPs & Weekly gross rating points (GRPs) of TV advertising & Offline (FIC) \\
\hline & Radio GRPs & Weekly gross rating points (GRPs) of Radio advertising & Offline (FIC) \\
\hline & Circulars & Weekly number of circulars distributed & Offline (FIC) \\
\hline & Store Traffic & Weekly traffic to offline store & Performance \\
\hline
\end{tabular}


Table 3: Summary statistics

\begin{tabular}{|c|c|c|c|c|c|}
\hline Firm & Variable & Mean & SD & Min & Max \\
\hline \multirow{7}{*}{ Brand A } & Organic Site Visits & 523.88 & 380.24 & 53.00 & 1386 \\
\hline & Paid Search & 4781.67 & 2694.72 & 0 & 12225.74 \\
\hline & Amazon Display Ads & 21.90 & 144.07 & 0 & 1153.85 \\
\hline & US News Display Ads & 315.47 & 799.70 & 0 & 3373.34 \\
\hline & Direct Visits & 3554.34 & 2532.83 & 125.00 & 10477.00 \\
\hline & Price & 627.64 & 48.15 & 501.25 & 799 \\
\hline & Revenues & $2.58 \mathrm{E}+05$ & $2.47 \mathrm{E}+05$ & 799 & $1.03 \mathrm{E}+06$ \\
\hline \multirow{8}{*}{ Brand B } & Web visits & 4013.5 & 1151.7 & 1507 & 7425 \\
\hline & Paid Search & 1325.5 & 476.05 & 619.39 & 2689.9 \\
\hline & Direct Mail & 4790.3 & 9022.1 & 0 & 42774 \\
\hline & Fax & 275.13 & 1027.9 & 0 & 7065.9 \\
\hline & Catalog & 854.01 & 5083 & 0 & 47728 \\
\hline & Discounts & 0.10572 & 0.030507 & 0.03488 & 0.22639 \\
\hline & eMail & 4319.9 & 4895.2 & 0 & 19587 \\
\hline & Sales revenues & $2.04 \mathrm{E}+05$ & 72621 & 52818 & $4.79 \mathrm{E}+05$ \\
\hline \multirow{8}{*}{ Brand C } & Organic Site Visits & $2.11 \mathrm{E}+06$ & $6.39 \mathrm{E}+05$ & $1.05 \mathrm{E}+06$ & $3.41 \mathrm{E}+06$ \\
\hline & Display Ads & $1.62 \mathrm{E}+07$ & $2.56 \mathrm{E}+07$ & 0 & $9.14 \mathrm{E}+07$ \\
\hline & Paid Search & $1.03 \mathrm{E}+07$ & $3.36 \mathrm{E}+06$ & 0 & $1.91 \mathrm{E}+07$ \\
\hline & Search on partners & $1.87 \mathrm{E}+07$ & $8.99 \mathrm{E}+06$ & 0 & $3.76 \mathrm{E}+07$ \\
\hline & Organic Google traffic & 16.758 & 4.7903 & 9.1925 & 27.636 \\
\hline & TV ads & 25157 & 50022 & 0 & $2.17 \mathrm{E}+05$ \\
\hline & Out of home & $5.76 \mathrm{E}+06$ & $1.38 \mathrm{E}+07$ & 0 & $4.51 \mathrm{E}+07$ \\
\hline & Revenues & $9.23 \mathrm{E}+05$ & $1.94 \mathrm{E}+05$ & $5.35 \mathrm{E}+05$ & $1.37 \mathrm{E}+06$ \\
\hline \multirow{9}{*}{ Brand D } & Owned Site Visits & $1.62 \mathrm{E}+06$ & $4.75 \mathrm{E}+05$ & $8.40 \mathrm{E}+05$ & $4.29 \mathrm{E}+06$ \\
\hline & Paid search & $1.30 \mathrm{E}+06$ & $4.19 \mathrm{E}+05$ & $7.28 \mathrm{E}+05$ & $3.23 \mathrm{E}+06$ \\
\hline & Display Ads & $1.89 \mathrm{E}+07$ & $6.15 \mathrm{E}+07$ & 0 & $3.49 \mathrm{E}+08$ \\
\hline & Earned General & 2328.5 & 3177.6 & 0 & 15035 \\
\hline & Organic Google search & 40.504 & 13.285 & 0 & 96.789 \\
\hline & TV GRPs & 134.73 & 114.67 & 0 & 389.4 \\
\hline & Radio GRPs & 21.029 & 48.059 & 0 & 177.66 \\
\hline & Circulars & $1.03 \mathrm{E}+05$ & $2.13 \mathrm{E}+05$ & 0 & $1.03 \mathrm{E}+06$ \\
\hline & Store Traffic & $6.77 \mathrm{E}+06$ & $1.86 \mathrm{E}+06$ & $2.02 \mathrm{E}+06$ & $1.45 \mathrm{E}+07$ \\
\hline
\end{tabular}


Table 4: Predictive Performance (MAPE)*

\begin{tabular}{|l|l|l|l|}
\hline Brand & in-sample & $\begin{array}{l}\text { one-step } \\
\text { ahead }\end{array}$ & $\begin{array}{l}\text { h-step } \\
\text { ahead }\end{array}$ \\
\hline Brand A & $17.65 \%$ & $16.90 \%$ & $18.49 \%$ \\
\hline Brand B & $1.75 \%$ & $2.35 \%$ & $3.76 \%$ \\
\hline Brand C & $3.93 \%$ & $4.43 \%$ & $10.46 \%$ \\
\hline Brand D & $10.15 \%$ & $9.61 \%$ & $13.17 \%$ \\
\hline
\end{tabular}

* MAPE denotes the Mean Absolute Percentage Error over the holdout sample. One-step ahead forecasts update each consecutive period, while multi-step forecasts predict without updating. Hold-out sample contains 14, 34, 25 and 24 observations for Brands A, B, C and D, respectively. 
Table 5: Main effects: BVAR and OLS Estimation Results* Unfamiliar/Service Brand A

Familiar/Service Brand C

\begin{tabular}{|l|l|c|c|l|l|}
\hline & & \multicolumn{2}{|c|}{ BVAR Results } & \multicolumn{2}{c|}{ OLS Results } \\
\hline Classification & \multicolumn{1}{|c|}{ Variables } & $\begin{array}{c}\text { Immediate } \\
\text { Effect }\end{array}$ & $\begin{array}{c}\text { Cumulative } \\
\text { Effect }\end{array}$ & Coefficient & $\begin{array}{c}\text { Long- } \\
\text { term } \\
\text { Effect }\end{array}$ \\
\hline Lagged DV & AR(1) & 0.646 & & 0.353 & \\
\hline Online (CIC) & Organic Site Visits & 0.135 & 0.135 & 0.240 & 0.371 \\
\hline Online (CIC) & Paid Search & 0.077 & 0.077 & 0.423 & 0.654 \\
\hline Online (CIC) & $\begin{array}{l}\text { Amazon Display } \\
\text { Ads }\end{array}$ & n.s. & n.s. & n.s. & n.s. \\
\hline Online (CIC) & $\begin{array}{l}\text { US News Display } \\
\text { Ads }\end{array}$ & n.s. & n.s. & n.s. & n.s. \\
\hline Online (CIC) & Direct Visits & 0.200 & 0.522 & 0.129 & 0.199 \\
\hline Offline (FIC) & Price & n.s. & n.s. & n.s. & n.s. \\
\hline
\end{tabular}

\begin{tabular}{|l|l|c|c|l|c|}
\hline & & \multicolumn{2}{|c|}{ BVAR Results } & \multicolumn{2}{c|}{ OLS Results } \\
\hline Classification & Variables & $\begin{array}{l}\text { Immediate } \\
\text { Effect }\end{array}$ & $\begin{array}{c}\text { Cumulative } \\
\text { Effect }\end{array}$ & Coefficient & $\begin{array}{c}\text { Long- } \\
\text { term } \\
\text { Effect }\end{array}$ \\
\hline Lagged DV & AR(1) & 0.611 & & 0.292 & \\
\hline Online (CIC) & Organic Site Visits & 0.162 & 0.481 & 0.348 & 0.492 \\
\hline Online (CIC) & Display Ads & 0.001 & 0.001 & 0.191 & 0.270 \\
\hline Online (CIC) & Paid Search & 0.007 & 0.007 & 0.016 & 0.023 \\
\hline Online (CIC) & Search on Partners & 0.006 & 0.006 & n.s. & n.s. \\
\hline Online (CIC) & $\begin{array}{l}\text { Organic Google } \\
\text { Traffic }\end{array}$ & 0.198 & 0.557 & 0.569 & 0.804 \\
\hline Offline (FIC) & TV ads & 0.003 & 0.003 & 0.059 & 0.083 \\
\hline Offline (FIC) & Out of home & n.s. & n.s. & n.s. & n.s. \\
\hline
\end{tabular}

Unfamiliar/Product Brand B

\begin{tabular}{|l|l|c|c|l|l|}
\hline & & \multicolumn{2}{|c|}{ BVAR Results } & \multicolumn{2}{c|}{ OLS Results } \\
\hline Classification & Variables & $\begin{array}{c}\text { Immediate } \\
\text { Effect }\end{array}$ & $\begin{array}{c}\text { Cumulative } \\
\text { Effect }\end{array}$ & Coefficient & $\begin{array}{c}\text { Long- } \\
\text { term } \\
\text { Effect }\end{array}$ \\
\hline Lagged DV & AR(1) & 0.355 & & 0.333 & \\
\hline Online (CIC) & Web visits & 0.190 & 0.362 & 0.139 & 0.208 \\
\hline Online (CIC) & Paid Search & n.s. & 0.279 & n.s. & n.s. \\
\hline Offline (FIC) & Direct Mail & 0.010 & 0.017 & 0.195 & 0.292 \\
\hline Offline (FIC) & Fax & 0.012 & 0.012 & 0.218 & 0.327 \\
\hline Offline (FIC) & Catalog & n.s. & n.s. & n.s. & n.s. \\
\hline Offline (FIC) & eMail & n.s. & n.s. & n.s. & n.s. \\
\hline Offline (FIC) & Discounts & 5.877 & 5.877 & 0.410 & 0.615 \\
\hline
\end{tabular}

Familiar/Product Brand D

\begin{tabular}{|c|c|c|c|c|c|}
\hline \multirow[b]{2}{*}{ Classification } & \multirow[b]{2}{*}{ Variables } & \multicolumn{2}{|c|}{ BVAR Results } & \multicolumn{2}{|c|}{ OLS Results } \\
\hline & & $\begin{array}{l}\text { Immediate } \\
\text { Effect }\end{array}$ & $\begin{array}{l}\text { Cumulative } \\
\text { Effect }\end{array}$ & Coefficient & $\begin{array}{c}\text { Long- } \\
\text { term } \\
\text { Effect }\end{array}$ \\
\hline Lagged DV & $\mathrm{AR}(1)$ & 0.534 & & 0.533 & \\
\hline Owned & Owned Site Visits & 0.198 & 0.231 & 0.148 & 0.317 \\
\hline Paid & Paid Search & 0.693 & 0.935 & 0.139 & 0.298 \\
\hline Paid & Display Ads & n.s. & n.s. & n.s. & n.s. \\
\hline Earned & Earned General & n.s. & n.s. & n.s. & n.s. \\
\hline Earned & $\begin{array}{l}\text { Organic Google } \\
\text { Search }\end{array}$ & 0.957 & 1.339 & 0.208 & 0.445 \\
\hline Offline & TV GRPs & 0.004 & 0.005 & 0.153 & 0.328 \\
\hline Offline & Radio GRPs & n.s. & n.s. & 0.123 & 0.263 \\
\hline Offline & Circulars & 0.003 & 0.003 & 0.182 & 0.390 \\
\hline
\end{tabular}

* All shown effects are significant at the $10 \%$ level, the others are indicated as not significant ('n.s.'). The long-term effect from the OLS estimation is calculated as : short-term estimate / (1- AR coefficient). 
.Table 6: Full model: BVAR and OLS Estimation Results (with interactions)

\begin{tabular}{|l|l|c|c|l|l|}
\hline \multicolumn{2}{|l|}{ Unfamiliar/Service Brand A } & \multicolumn{2}{|c|}{ BVAR Results } & \multicolumn{2}{c|}{ OLS Results } \\
\hline Classification & Variables & $\begin{array}{c}\text { Immediate } \\
\text { Effect }\end{array}$ & $\begin{array}{c}\text { Cumulative } \\
\text { Effect }\end{array}$ & $\begin{array}{c}\text { OLS } \\
\text { Coefficient }\end{array}$ & $\begin{array}{c}\text { Long-term } \\
\text { Effect }\end{array}$ \\
\hline & Main Variables & & & & \\
\hline Lagged DV & AR(1) & 0.619 & & 0.430 & \\
\hline Online (CIC) & Organic Site Visits & 0.148 & 0.394 & 0.185 & 0.325 \\
\hline Online (CIC) & Paid Search & 0.075 & 0.096 & 0.407 & 0.714 \\
\hline Online (CIC) & Amazon Display Ads & n.s. & n.s. & n.s. & n.s. \\
\hline Online (CIC) & US News Display Ads & n.s. & n.s. & n.s. & n.s. \\
\hline Online (CIC) & Direct Visits & 0.167 & 0.435 & 0.119 & 0.209 \\
\hline Offline (FIC) & Price & n.s. & n.s. & n.s. & n.s. \\
\hline & $\begin{array}{l}\text { All Significant } \\
\text { Interactions }\end{array}$ & & & & \\
\hline Offline*Online & $\begin{array}{l}\text { Price*Organic Site } \\
\text { Visits }\end{array}$ & 0.145 & 0.374 & 0.094 & 0.165 \\
\hline Offline*Online & Price*Direct Visits & 0.168 & 0.428 & n.s. & n.s. \\
\hline Offline*Online & Price*Paid Search & 0.054 & 0.069 & 0.603 & 1.058 \\
\hline Online*Online & $\begin{array}{l}\text { Organic Site } \\
\text { Visits*Direct Visits }\end{array}$ & 0.095 & 0.250 & 0.079 & 0.139 \\
\hline Online*Online & $\begin{array}{l}\text { Organic Site } \\
\text { Visits*Paid Search }\end{array}$ & 0.055 & 0.072 & 0.062 & 0.109 \\
\hline Online*Online & $\begin{array}{l}\text { Direct Visits*Paid } \\
\text { Search }\end{array}$ & 0.053 & 0.070 & 0.109 & 0.191 \\
\hline
\end{tabular}

Familiar / Service Brand C
\begin{tabular}{|l|l|c|c|c|l|}
\hline \multicolumn{3}{|l|}{} & \multicolumn{2}{|c|}{ BVAR Results } & \multicolumn{2}{c|}{ OLS Results } \\
\hline Classification & Variables & $\begin{array}{c}\text { Immediate } \\
\text { Effect }\end{array}$ & $\begin{array}{c}\text { Cumulative } \\
\text { Effect }\end{array}$ & $\begin{array}{c}\text { OLS } \\
\text { Coefficient }\end{array}$ & $\begin{array}{c}\text { Long-term } \\
\text { Effect }\end{array}$ \\
\hline & \multicolumn{2}{|l|}{ Main Variables } & & \\
\hline Lagged DV & AR(1) & 0.672 & & 0.809 & \\
\hline Online (CIC) & Organic Site Visits & 0.557 & 0.557 & 0.199 & 1.042 \\
\hline Online (CIC) & Display Ads & n.s. & n.s. & 0.117 & 0.613 \\
\hline Online (CIC) & Paid Search & 0.009 & 0.009 & 0.015 & 0.079 \\
\hline Online (CIC) & Search on Partners & 0.008 & 0.008 & 0.394 & 2.063 \\
\hline Online (CIC) & Organic Google Traffic & 0.898 & 1.036 & 0.907 & 4.749 \\
\hline Offline (FIC) & TV ads & 0.008 & 0.008 & 0.165 & 0.864 \\
\hline Offline (FIC) & Out of home & n.s. & n.s. & n.s. & n.s. \\
\hline & $\begin{array}{l}\text { All Significant } \\
\text { Interactions }\end{array}$ & & & & \\
\hline Online*Offline & Display Ads*TV Ads & 0.003 & 0.003 & 0.103 & 0.539 \\
\hline Online*Offline & Paid Search*TV Ads & 0.003 & 0.003 & 0.726 & 3.801 \\
\hline Online*Offline & $\begin{array}{l}\text { Search on Partners*TV } \\
\text { Ads }\end{array}$ & 0.003 & 0.003 & 0.704 & 3.686 \\
\hline Online*Offline & $\begin{array}{l}\text { Org. Google } \\
\text { Traffic*TV ads }\end{array}$ & 0.006 & 0.006 & 0.203 & 1.063 \\
\hline Online*Online & $\begin{array}{l}\text { Org. Google } \\
\text { Traffic*Org. Site Visits }\end{array}$ & 0.451 & 0.451 & n.s. & n.s. \\
\hline Online*Offline & $\begin{array}{l}\text { TV Ads*Org. Site } \\
\text { Visits }\end{array}$ & 0.003 & 0.003 & 0.132 & 0.691 \\
\hline Offline*Offline & TV Ads*Out of home & 0.001 & 0.001 & n.s. & n.s. \\
\hline
\end{tabular}

* All shown effects are significant at the $10 \%$ level, the others are indicated as not significant ('n.s.'). The long-term effect from the OLS estimation is calculated as : short-term estimate / (1- AR coefficient). 
Table 6 (cont'd):

Unfamiliar / Product Brand B

\begin{tabular}{|l|l|c|c|l|l|}
\hline \multicolumn{2}{|l|}{} & \multicolumn{2}{|c|}{ BVAR Results } & \multicolumn{2}{c|}{ OLS Results } \\
\hline Classification & Variables & $\begin{array}{l}\text { Immediate } \\
\text { Effect }\end{array}$ & $\begin{array}{c}\text { Cumulative } \\
\text { Effect }\end{array}$ & $\begin{array}{c}\text { OLS } \\
\text { Coefficient }\end{array}$ & $\begin{array}{c}\text { Long- } \\
\text { term } \\
\text { Effect }\end{array}$ \\
\hline & Main Variables & & & \\
\hline Lagged DV & AR(1) & 0.606 & & 0.289 & \\
\hline Online (CIC) & Web visits & 0.225 & 0.407 & 0.215 & 0.302 \\
\hline Online (CIC) & Paid Search & n.s. & 0.199 & n.s. & n.s. \\
\hline Offline (FIC) & Direct Mail & 0.021 & 0.036 & 0.209 & 0.294 \\
\hline Offline (FIC) & Fax & 0.024 & 0.024 & 0.306 & 0.430 \\
\hline Offline (FIC) & Catalog & n.s. & n.s. & n.s. & n.s. \\
\hline Offline (FIC) & eMail & 0.008 & 0.008 & n.s. & n.s. \\
\hline Offline (FIC) & Discounts & 6.601 & 6.601 & 0.425 & 0.598 \\
\hline & $\begin{array}{l}\text { All Significant } \\
\text { Interactions }\end{array}$ & & & & \\
\hline Offline*Offline & Direct Mail*Fax & 0.029 & 0.029 & n.s. & n.s. \\
\hline Offline*Offline & $\begin{array}{l}\text { Direct Mail } \\
* \text { Discounts }\end{array}$ & 0.028 & 0.049 & 0.777 & 1.093 \\
\hline Offline*Offline & Direct Mail*Email & 0.011 & 0.019 & 0.001 & 0.001 \\
\hline Offline*Online & $\begin{array}{l}\text { Direct Mail*Web } \\
\text { Visits }\end{array}$ & 0.011 & 0.020 & 0.171 & 0.241 \\
\hline Offline*Online & $\begin{array}{l}\text { Direct Mail*Paid } \\
\text { Search }\end{array}$ & 0.069 & 0.069 & n.s. & n.s. \\
\hline Offline*Offline & Fax*Discounts & 0.035 & 0.035 & 0.094 & 0.132 \\
\hline Offline*Offline & Fax*Mail & 0.036 & 0.036 & 0.004 & 0.006 \\
\hline Offline*Online & Fax*Web Visits & 0.012 & 0.012 & n.s. & n.s. \\
\hline Offline*Online & Discounts*Web Visits & 0.461 & 0.554 & n.s. & n.s. \\
\hline Online*Online & $\begin{array}{l}\text { Paid Search*Web } \\
\text { Visits }\end{array}$ & 0.004 & 0.004 & n.s. & n.s. s. \\
\hline
\end{tabular}

Familiar / Product Brand D

\begin{tabular}{|l|l|c|c|l|l|}
\hline \multicolumn{2}{|l|}{ Familiar/Product Brand D } & \multicolumn{2}{|c|}{ BVAR Results } & \multicolumn{2}{c|}{ OLS Results } \\
\hline Classification & Variables & $\begin{array}{c}\text { Immediate } \\
\text { Effect }\end{array}$ & $\begin{array}{c}\text { Cumulative } \\
\text { Effect }\end{array}$ & $\begin{array}{c}\text { OLS } \\
\text { Coefficient }\end{array}$ & $\begin{array}{c}\text { Long-term } \\
\text { Effect }\end{array}$ \\
\hline & Main Variables & 0.407 & & 0.244 & \\
\hline Lagged DV & AR(1) & 0.176 & 0.102 & n.s. & n.s. \\
\hline Online (CIC) & Owned Site Visits & 0.617 & 0.483 & 0.284 & 0.376 \\
\hline Online (CIC) & Paid Search & -0.003 & -0.002 & n.s. & n.s. \\
\hline Online (CIC) & Display Ads & n.s. & n.s. & n.s. & n.s. \\
\hline Online (CIC) & Earned General & 0.874 & 0.766 & 0.512 & 0.677 \\
\hline Online (CIC) & Organic Google Search & 0.006 & 0.006 & 0.297 & 0.393 \\
\hline Offline (FIC) & TV GRPs & 0.004 & 0.004 & n.s. & n.s. \\
\hline Offline (FIC) & Radio GRPs & 0.004 & 0.004 & 0.174 & 0.230 \\
\hline Offline (FIC) & Circulars & 0.006 & 0.006 & n.s. & n.s. \\
\hline & All Significant Interactions & & & & n.s. \\
\hline Offline*Offline & TV*Radio & 0.005 & 0.005 & n.s. & \\
\hline Offline*Offline & TV*Circulars & 0.003 & 0.003 & 0.025 & 0.033 \\
\hline Offline*Online & TV*Paid Search & 0.004 & 0.004 & 0.405 & 0.536 \\
\hline Offline*Online & Radio*Org. Google Search & 0.002 & 0.002 & n.s. & n.s. \\
\hline Offline*Online & Circulars*Owned Site Vis. & 0.002 & 0.002 & n.s. & n.s. \\
\hline Offline*Online & Circulars*Paid Search & 0.003 & 0.003 & 1.125 & 1.488 \\
\hline Offline*Online & Circulars*Org. Google Search & 0.218 & 0.177 & 0.089 & 0.118 \\
\hline Online*Online & Owned Site Vis.*Paid Search & 0.218 & n.s. \\
\hline Online*Online & $\begin{array}{l}\text { Owned Site Vis.*Org. Google } \\
\text { Search }\end{array}$ & 0.286 & 0.213 & n.s. & 0.556 \\
\hline Online*Online & $\begin{array}{l}\text { Paid Search*Org. Google } \\
\text { Search }\end{array}$ & 0.419 & 0.336 & 0.420 & \\
\hline
\end{tabular}

* All shown effects are significant at the 10\% level, the others are indicated as not significant ('n.s.'). The long-term effect from the OLS estimation is calculated as : short-term estimate / (1- AR coefficient) 
Table 7: Cumulative Elasticity Results on Synergy of Online and Offline Media

Typical Action

Unfamiliar Brand A

\begin{tabular}{|c|c|c|c|}
\hline Classification & Median & Hypothesis & T-stat \\
\hline $\begin{array}{c}\text { Cross-channel } \\
\text { synergy }\end{array}$ & 0.374 & H1 (Supported) & $2.04 *$ \\
\hline $\begin{array}{c}\text { Within-Online } \\
\text { synergy }\end{array}$ & 0.072 & & \\
\hline
\end{tabular}

Unfamiliar Brand B

\begin{tabular}{|c|c|c|c|}
\hline Classification & Median & Hypothesis & T-stat \\
\hline Cross-synergy & 0.044 & $\mathrm{H} 1$ & 0.57 \\
\hline $\begin{array}{c}\text { Within-Online } \\
\text { synergy }\end{array}$ & 0.004 & & \\
\hline
\end{tabular}

Familiar Brand C

\begin{tabular}{|c|c|c|c|}
\hline Classification & Median & Hypothesis & T-stat \\
\hline $\begin{array}{c}\text { Within-Online } \\
\text { synergy }\end{array}$ & 0.451 & H2 (Supported) & $11.72 * * *$ \\
\hline $\begin{array}{c}\text { Cross-channel } \\
\text { synergy }\end{array}$ & 0.003 & & \\
\hline
\end{tabular}

Familiar Brand D

\begin{tabular}{|c|c|c|l|}
\hline Classification & Median & Hypothesis & T-stat \\
\hline $\begin{array}{c}\text { Within-Online } \\
\text { synergy }\end{array}$ & 0.213 & & \\
\hline $\begin{array}{c}\text { Cross-channel } \\
\text { synergy }\end{array}$ & 0.003 & H2 (Supported) & $7.36 * * *$ \\
\hline
\end{tabular}

Best-in-breed Action

Unfamiliar Brand A

\begin{tabular}{|c|c|c|c|}
\hline Classification & Max. & \multicolumn{2}{|c|}{ Hypothesis } \\
\hline $\begin{array}{c}\text { Cross-channel } \\
\text { synergy }\end{array}$ & 0.428 & H1 & 0.99 \\
\hline $\begin{array}{c}\text { Within-Online } \\
\text { synergy }\end{array}$ & 0.250 & & \\
\hline
\end{tabular}

Unfamiliar Brand B

\begin{tabular}{|l|c|c|c|}
\hline Classification & Max. & Hypothesis & T-stat \\
\hline Cross-synergy & 0.554 & & H1 (Supported) \\
\cline { 1 - 2 } $\begin{array}{c}\text { Within-Online } \\
\text { synergy }\end{array}$ & 0.004 & & \\
\hline
\end{tabular}

Familiar Brand C

\begin{tabular}{|c|c|c|c|}
\hline Classification & Max. & Hypothesis & T-stat \\
\hline $\begin{array}{l}\text { Within-Online } \\
\text { synergy }\end{array}$ & 0.451 & \multirow{2}{*}{ H2 (Supported) } & \multirow{2}{*}{$28.05^{* * *}$} \\
\hline $\begin{array}{c}\text { Cross-channel } \\
\text { synergy }\end{array}$ & 0.006 & & \\
\hline
\end{tabular}

Familiar Brand D

\begin{tabular}{|c|c|c|c|}
\hline Classification & Max. & Hypothesis & T-stat \\
\hline $\begin{array}{l}\text { Within-Online } \\
\text { synergy }\end{array}$ & 0.336 & \multirow{2}{*}{ H2 (Supported) } & \multirow{2}{*}{$13.20 * * *$} \\
\hline $\begin{array}{l}\text { Cross-channel } \\
\text { synergy }\end{array}$ & 0.004 & & \\
\hline
\end{tabular}

Note: ***, * signs imply the significance level at 99\% level (p <.01), and 90\% level (p<.10), respectively. 
Table 8: Marketing Budget Allocation options for brand B

\begin{tabular}{|c|c|c|c|c|c|}
\hline $\begin{array}{c}\text { Media } \\
\text { type }\end{array}$ & $\begin{array}{c}\text { Current } \\
\text { Allocation }\end{array}$ & $\begin{array}{c}\text { Main Effects } \\
\text { Allocation }\end{array}$ & $\begin{array}{c}\text { Allocation } \\
\text { Range }\end{array}$ & $\begin{array}{l}\text { Synergies } \\
\text { Allocation }\end{array}$ & $\begin{array}{c}\text { Allocation } \\
\text { Range }\end{array}$ \\
\hline $\begin{array}{c}\text { Paid } \\
\text { Search }\end{array}$ & $18.30 \%$ & $90.56 \%$ & $\begin{array}{c}\text { [68.93\% ; } \\
90.89 \%]\end{array}$ & $44.52 \%$ & $\begin{array}{c}{[41.66 \%} \\
45.70 \%]\end{array}$ \\
\hline $\begin{array}{c}\text { Direct } \\
\text { Mail }\end{array}$ & $66.12 \%$ & $5.68 \%$ & $\begin{array}{c}{[19.52 \%} \\
4.27 \%]\end{array}$ & $36.88 \%$ & $\begin{array}{c}39.57 \% ; \\
31.31 \%]\end{array}$ \\
\hline Fax & $3.80 \%$ & $3.76 \%$ & $\begin{array}{c}{[11.55 \%} \\
2.97 \%]\end{array}$ & $18.60 \%$ & $\begin{array}{c}{[18.77 \% ;} \\
20.44 \%]\end{array}$ \\
\hline Catalog & $11.79 \%$ & $0.00 \%$ & $\begin{array}{c}{[0.00 \% ;} \\
1.88 \%]\end{array}$ & $0.00 \%$ & $\begin{array}{c}{[0.00 \% ;} \\
2.55 \%]\end{array}$ \\
\hline
\end{tabular}

* Note: Main effects allocation is based on the point estimates while allocation range is calculated based on $+/$ - one standard error bands. 


\section{Technical Appendix}

\section{A1: Bayesian Vector Autoregression (BVAR) Modeling Steps}

Our BVAR modeling approach consists of the following 5 steps:

Step 1: In the first step, we simply consider the unrestricted VAR (k) model and do not impose restrictions on the coefficients of the VAR model. The optimal lag length is chosen based on the Schwarz Information Criterion (SIC) which is commonly used in the marketing literature (e.g. Pauwels et al. 2004). We opt for taking natural logarithm (adding 0.0001 to avoid the log of 0 ) to smooth the variables' distribution and efficiently model diminishing returns. Unit root testing (e.g. Pauwels et al. 2002) is not applicable to the Bayesian estimation as unit roots do not affect the likelihood function (Sims, Stock and Watson 1990).

Step 2: After building the VAR model, the second step is to impose the restrictions on the coefficients of the VAR model by using the set of Minnesota parameters in Eq. (4). In order to find the best parameters, we consider three values for the weight parameter, $w: 0.25,0.5$ and 0.75 . For the tightness parameter $\theta$, we assume four different values: $0.5,0.3,0.1$ and 0.05 . The first number (0.5) is a relatively loose value while the last number (0.05) is a tight value. We chose the lag decay parameter $\phi$ to be 1 as suggested by Doan et al. (1984). As a result, we determine the set of the hyperparameter values, i.e. $w, \theta, \phi$.

Step 3: With the selected parameters from Step 2, we estimate BVAR(k) model ${ }^{10}$. As explained in the methodology section, the estimation method is Theil and Goldberger's mixed estimation technique.

\footnotetext{
${ }^{10}$ We do not perform Granger causality tests as they are invalid given the Bayesian prior applied to the model (LeSage 1999, page 128).
} 
Step 4: We calculate the Generalized Impulse Response Functions (GIRF) (simultaneous shocking approach) using the formula by Pesaran and Shin (1998). To find the standard errors of GIRF coefficients we employ the residual-based bootstrap technique. Specifically, we (a) bootstrap the residuals of the BVAR(k) model, (b) obtain bootstrapped data using the estimated parameters and the bootstrapped residuals and (c) obtain new BVAR coefficient estimates and GIRF coefficient estimates using the bootstrapped data. We repeat these steps 500 times and then calculate the standard errors of the GIRF coefficients.

Step 5: After finding the bootstrapped standard errors, we assess whether each impulseresponse value is significantly different from zero as suggested by VAR-related literature in marketing (e.g. Pauwels, Hanssens and Siddarth 2002). Finally, we compute the immediate and cumulative effects based on the significant GIRF estimates.

\section{A2: Budget allocation approach in the absence and presence of synergy}

We assume companies aim to maximize profits, which leads to the well-established advice (in the absence of synergy) that the budget allocation across different media spending should follow their ratio of marginal elasticities (e.g. Dorfman and Steiner 1954, Wright 2009). The presence of synergy requires us to update this advice, as we illustrate below. Consider the log-log specification for the following model without interactions:

$$
y=\alpha+\beta_{1} X_{1}+\beta_{2} X_{2}+\varepsilon
$$

where $\varepsilon$ is the residual term with i.i.d. normal. For simplicity, we do not include the time index in the notation. Taking the first derivative of Eq.A1 with respect to $X_{1}$ and $X_{2}$ respectively, we obtain the following marginal elasticities:

$$
\frac{\partial y}{\partial X_{1}}=\beta_{1} \text { and } \frac{\partial y}{\partial X_{2}}=\beta_{2}
$$


Then, the budget allocation based on these estimated elasticities becomes $\frac{\beta_{1}}{\beta_{1}+\beta_{2}}$ for $X_{1}$, and $\frac{\beta_{2}}{\beta_{1}+\beta_{2}}$ for $X_{2}$. Now, let us add the interaction (synergy) term to equation A1:

$$
y=\alpha+\beta_{1} X_{1}+\beta_{2} X_{2}+\gamma_{1}\left(X_{1} \times X_{2}\right)+\varepsilon
$$

where $\varepsilon$ is the residual term with i.i.d. normal.

Taking the first derivative of Eq. A2 with respect to $X_{1}$ and $X_{2}$ respectively, we get

$\frac{\partial y}{\partial X_{1}}=\beta_{1}+\gamma_{1} X_{2}$ and $\frac{\partial y}{\partial X_{2}}=\beta_{2}+\gamma_{1} X_{1}$

Then, the budget allocation becomes

$\frac{\beta_{1}+\gamma_{1} X_{2}}{\left(\beta_{1}+\gamma_{1} X_{2}\right)+\left(\beta_{2}+\gamma_{1} X_{1}\right)}$ for $X_{1}$, and

$\frac{\beta_{2}+\gamma_{1} X_{1}}{\left(\beta_{1}+\gamma_{1} X_{2}\right)+\left(\beta_{2}+\gamma_{1} X_{1}\right)}$ for $X_{2}$

Note that marginal elasticity of $X_{1}$ changes depending on the level of $X_{2}$. Likewise, the marginal elasticity of $X_{2}$ changes depending on the level of $X_{1}$. We assess the elasticity at the mean values of the variables. In other words, using the above simple example, our allocation is as follows:

$$
\begin{aligned}
& \frac{\beta_{1}+\gamma_{1} \bar{X}_{2}}{\left(\beta_{1}+\gamma_{1} \bar{X}_{2}\right)+\left(\beta_{2}+\gamma_{1} \bar{X}_{1}\right)} \text { for } X_{1} \text {, and } \\
& \frac{\beta_{2}+\gamma_{1} \bar{X}_{1}}{\left(\beta_{1}+\gamma_{1} \bar{X}_{2}\right)+\left(\beta_{2}+\gamma_{1} \bar{X}_{1}\right)} \text { for } X_{2} .
\end{aligned}
$$

where the notation $\bar{X}$ represents the mean value. 